\title{
A reforma da educação básica no Ceará
}

\author{
ANTENOR NASPOLINI
}

$\mathrm{O}$

CEARÁ É o estado com maior extensão territorial no semi-árido brasileiro, ambiente que favoreceu uma ocupação baseada em culturas de subsistência: a pecuária, o extrativismo, a agricultura e a indústria periférica. As condições climáticas associaram-se a um modelo social gerado por contornos políticos e econômicos baseados na exploração de mão-de-obra desqualificada. Embora o governo estadual esteja fazendo esforços concentrados na área de alfabetização de adultos, o Ceará ainda apresenta um índice de 27,8 \% (1999) de analfabetos entre jovens e adultos de 15 anos e mais, contra o índice nacional de 13,3\% para a mesma faixa etária em 1999.

Com o processo de redemocratização do país, em 1985, teve início no estado um movimento político-econômico que veio a chamar-se mudancismo, que se contrapôs ao coronelismo (1968-1986). O mudancismo tem sido marcado por uma série de reformas de estado (Administrativa e Fiscal, 1986-1990; Saúde, 1986-1990; Infra-estrutura e Privatizações, 1991-1999 e Educacional, 1995-2000). Do ponto de vista econômico, o mudancismo é responsável pela segunda onda de industrialização do estado, com a instalação, entre 1991-1999, de 450 empresas cujo modelo veio a se mostrar como concentrador de renda, mesmo o Ceará tendo crescido mais que a média nacional.

Três elementos apoiaram a reforma de educação básica cearense, entre 1995 e 2000:

- uma reconhecida necessidade de mudança, expressa nos planos de governo dos últimos 12 anos;

- contexto econômico e político favorável, traduzido pelo saneamento das finanças do estado e a expressiva credibilidade de suas instituições; e

- a existência de mecanismos efetivos de participação social, evidenciados pela modernização das formas de gestão pública e pela atuação organizada da sociedade civil.

\section{O modelo de reforma da educação básica}

As reformas educacionais, em geral, podem adotar dois tipos de fluxo: o vertical, com decisões tomadas em níveis hierárquicos superiores e impostas aos 
outros níveis, e o horizontal, onde as decisões não ascendem ou não são compartilhadas entre os níveis hierárquicos. As reformas verticais, aparentemente, causam impacto imediato, algo que não é confirmado pela experiência, que aponta a insustentabilidade e precariedade destas reformas; as reformas horizontais tendem à estagnação e à consolidação de culturas, tornando os sistemas pouco flexíveis às mudanças.

O Ceará adotou um terceiro tipo de reforma, baseado na imagem de uma espiral, em que são combinados os fluxos vertical e horizontal.

Nesse modelo, as decisões transitam tanto a partir dos níveis hierárquicos superiores (como as secre-tarias municipais e estadual de educação), como a partir da base (conjunto de escolas). Embora o percurso possa parecer mais longo e demorado, este modelo mostra-se mais resistente às pressões políticas e econômicas, o que demonstra a sua capacidade de garantir a sustentabilidade e adaptabilidade às mudanças.

A construção desse modelo só é possível, portanto, se for feita de maneira coletiva e dialética: ao mesmo tempo todos participam e tomam decisões que consideram tanto a experiência local, na escola, como as demandas de estado.

A espiral de decisões do sistema educacional cearense se propôs a resolver a seguinte questão: como garantir a educação de qualidade para todos? A política educacional adotada assumiu ao mesmo tempo a proposta e a resposta: Todos pela Educação de Qualidade para Todos que sintetiza os pressupostos básicos das políticas públicas: acesso e qualidade a partir da mobilização social e da resposta do estado a estas demandas.

Em outros termos, a expressão sugere a mobilização social em torno do acesso universal à educação básica de qualidade, entendida, a partir da Declaração Mundial de Educação para Todos (Jomtien, Tailândia, 1990), como aquela que satisfaz e enfoca as necessidades básicas de aprendizagem, que promove a eqüidade, fortalece alianças, mobiliza recursos e contextualiza as políticas.

O primeiro e principal desafio da reforma da educação básica cearense foi o de resgatar a credibilidade de um sistema educacional precarizado, que não conseguia atrair, em 1995, mais que 65\% da população de 7 a 14 anos; o segundo desafio era o de captar recursos financeiros adicionais para um sistema de baixa qualidade.

No quadro 1 são apresentadas as principais metas elencadas no Plano Decenal de Educação para Todos (PDEPT, 1994) e no Projeto Áridas, os dois principais documentos de planejamento educacional editados antes de 1995, e os resultados alcançados até 2001, são apresentados em quatro categorias: acesso à educação básica, melhoria do perfil de desempenho qualitativo dos alunos, valorização do magistério e gestão democrática. 
QUADRO 01 - Metas de Acesso, Qualidade, Valorização do Magistério e Gestão da Educação Básica nos Planos Educacionais dos anos 90 e os resultados alcançados até 2001.

\begin{tabular}{|c|c|c|}
\hline \multicolumn{3}{|c|}{ ACESSO A EDUCAÇÃO BASICA } \\
\hline Nivel/Modalidado de Ensino & Descrição da Meta/ Projeção de Alcance & Alcance cm 2001 \\
\hline Educação Infantil & $\begin{array}{l}\text { a) Ingresso de } 60 \% \text { da população de } 5 \text { anos e } \\
80 \% \text { da população de } 6 \text { anos em } 2003 \text { (Plano } \\
\text { Decenal de Educação para Todos 1993-2003 } \\
\text { - PDEPT); } \\
\text { b) Ingresso de } 70 \% \text { da população de } 5 \text { anos e } \\
80 \% \text { da população de } 6 \text { anos em } 1998 \text { (Projeto } \\
\text { Áridas). }\end{array}$ & $\begin{array}{l}\text { Ingresso de } 64 \% \text { das crianças de } 5 \\
\text { anos e } 63 \% \text { das crianças de } 6 \text { anos } \\
\text { em } 1998 \text {. }\end{array}$ \\
\hline Ensino Fundamental & $\begin{array}{l}\text { a) Ingresso de } 80 \% \text { da população de } 7 \text { a } 14 \\
\text { anos cm } 2003 \text { (PDEPT); } \\
\text { b) Ingresso de } 85 \% \text { das crianças de } 7 \text { a } 14 \text { anos } \\
\text { até o ano de } 1998 \text { (Projeto Áridas). }\end{array}$ & $\begin{array}{l}\text { Ingresso de } 98 \% \text { das crianças de } 7 \text { a } \\
14 \text { anos } \mathrm{em} 1998 \text {. }\end{array}$ \\
\hline Ensino Médio & $\begin{array}{l}\text { Matricula de } 20 \% \text { da população de } 15 \text { a } 19 \text { anos } \\
\text { em } 1998 \text { (PDEPT e Projeto Äridas). }\end{array}$ & $\begin{array}{l}\text { Ingresso de } 18 \% \text { da população de } 15 \\
\text { a } 19 \text { anos no ensino médio. }\end{array}$ \\
\hline Educação de Jovens e Adultos & $\begin{array}{l}\text { Redução da taxa de analfabetismo para } 20 \% \text { da } \\
\text { população de } 15 \text { a } 39 \text { anos em } 1998 \text { (PDEPT e } \\
\text { Projeto Áridas) }\end{array}$ & $\begin{array}{l}\text { Taxa de Analfabetismo entre jovens } \\
\text { e adultos de } 15 \text { a } 39 \text { anos com até um } \\
\text { ano de escolaridade em 1996: } 22 \%\end{array}$ \\
\hline \multicolumn{3}{|c|}{ MELHORIA DO DESEMPENHO DOS ALUNOS } \\
\hline Ensino Fundamental & $\begin{array}{l}\text { Taxa de conclusão do Ensino Fundamental: } 70 \% \\
\text { dos concludentes do ensino fundamental em } 2003 \\
\text { em relação aos alunos que ingressaram em } 1996 \\
\text { (PDEPT). }\end{array}$ & $\begin{array}{l}\text { Em } 1998 \text { concluíram o Ensino } \\
\text { Fundamental } 35 \% \text { dos alunos que } \\
\text { ingressaram na primeira sćrie em } \\
\text { 1991. }\end{array}$ \\
\hline Ensino Médio & $\begin{array}{l}\text { Taxa de aprovação em torno de } 80 \% \text { até o ano } \\
2003 \text { (PDEPT). }\end{array}$ & $\begin{array}{l}\text { Em } 1997 \text { foi registrada a taxa de } \\
\text { aprovaçåo de } 76 \% \text {. }\end{array}$ \\
\hline \multicolumn{3}{|c|}{ VALORIZAÇĀO DO MAGISTÉRIO } \\
\hline Nivel/Modalidade de Ensino & Descrição da Meta/ Projeção de Alcance & Alcance $\mathrm{cm} 2001$ \\
\hline Educação Infantil & (sem previsão) & $\begin{array}{l}\text { a) Em } 2001 \text { a rede municipal } \\
\text { apresentou um indice de } 29,0 \% \text { de } \\
\text { professores năo habilitados na } \\
\text { Educação Infantil, contra } 70,63 \% \\
\text { registrados cm 1996. }\end{array}$ \\
\hline Ensino Fundamental & $\begin{array}{l}\text { a) Habilitação de } 58,1 \% \text { dos professores leigos da } \\
\text { rede municipal no periodo de } 1996 \text { até } 2002 \text {. } \\
\text { (Projeto Aridas) } \\
\text { b) Aumento real de salário de cerca de } 22 \% \text { ao } \\
\text { ano, até } 1998 \text { para alcançar o nível brasileiro. } \\
\text { (Projeto Aridas) }\end{array}$ & $\begin{array}{l}\text { a) Em } 2001 \text { a rede municipal de } \\
\text { ensino apresentou um indice de } \\
14,46 \% \text { do total de professores sem } \\
\text { habilitą̧ão. }\end{array}$ \\
\hline Ensino Médio & $\begin{array}{l}\text { a) dos professores da rede estadual } \\
\text { habilitados em nivel superior, no periodo } \\
\text { compreendido de } 1999 \text { até } 2003 \text {. (Projeto } \\
\text { Aridas); } \\
\text { b) Aumento real de salário de cerca de } 22 \% \text { ao } \\
\text { ano até } 1998 \text { para alcançar a média nacional. } \\
\text { (Projetos Aridas); } \\
\text { c) Contratação de } 282 \text { professores de } 1995 \text { a } \\
1998 \text { pela redução de } 25 \% \text { da repetência. } \\
\text { (Projto Aridas). }\end{array}$ & $\begin{array}{l}\text { a) Em } 2001 \text { a rede estadual registrou } \\
\text { um indice de } 91,38 \% \text { de habilitação } \\
\text { em nivel superior, } \\
\text { b) O reajuste salarial acumulado } \\
\text { entre } 1995 \text { e } 1998 \text {, na rede estadual, } \\
\text { foi de } 67,8 \% \text { a } 104,8 \% \text { em função } \\
\text { dos niveis da carreira. }\end{array}$ \\
\hline \multicolumn{3}{|c|}{ GESTÃO DEMOCRÁTICA } \\
\hline Política & Descrição da Meta/ Projeção de Alcance & Alcance em 2001 \\
\hline Municipalização & $\begin{array}{l}\text { Proposta de anteprojeto da Lei de Municipalização } \\
\text { de Ensino (PDEPT) }\end{array}$ & $\begin{array}{l}\text { Aprovação da Lei de } \\
\text { Municipalização(1996) }\end{array}$ \\
\hline Eleiçåo de Diretores & (sem previsào) & $\begin{array}{l}\text { Eleição de Diretores em escolas da } \\
\text { rede estadual }(1995,1998 \text { e 2001) } \\
\end{array}$ \\
\hline Descentralizą̧ão & $\begin{array}{l}\text { a)Reestruturação das Delegacias Regionais de } \\
\text { Educação (PDEPT); } \\
\text { b) Fortalecimento do Programa de Manutenção } \\
\text { das Escolas (PDEPT) }\end{array}$ & $\begin{array}{l}\text { a)Criação dos Centros Regionais de } \\
\text { Descnvolvimento de Educação com } \\
\text { provimento de cargos a partir de } \\
\text { seleção pública; } \\
\text { b) Criação do Fundo de Apoio ao } \\
\text { Desenvolvimento da Escola (1996). } \\
\end{array}$ \\
\hline $\begin{array}{l}\begin{array}{l}\text { Modernização } \\
\text { Educacional }\end{array} \\
\text { do }\end{array}$ & $\begin{array}{l}\text { Implantação do Sistema Integrado de Informações } \\
\text { Gerenciais (PDEPT/Projeto Nordeste) }\end{array}$ & $\begin{array}{l}\text { Implantação do Sistema Integrado de } \\
\text { Informações Gerenciais em 1996, } \\
\text { com informatização total da SEDUC. }\end{array}$ \\
\hline \multicolumn{3}{|c|}{$\begin{array}{l}\text { NOTAS: } \\
\text { 1) em } 98,70 \% \text { dos jovens de } 15 \text { a } 19 \text { anos foram matriculados na Educação Básica ,o que representa o total de } 567.451 \text { pessoas }\end{array}$} \\
\hline
\end{tabular}


A mobilização de todos os setores da sociedade cearense pela democratização do acesso à educação foi construída sobre os princípios da participação social em seminários regionais sobre a gestão democrática e municipalização do ensino (1995), reuniões técnicas, debates, eventos públicos e através do apoio e promoção de iniciativas como a instalação do Fórum Permanente da Educação (1996), o Acordo de Cooperação Técnica SEDUC/Universidades (1996), o Encontro Justiça na Educação - Um Pacto Cearense (1997), e o Programa Permanente de Apoio aos Secretários Municipais de Educação e Prefeituras (PRASEM e PRASEMPRE, 1997).

Os avanços registrados no Ceará, no período 1995/2000, podem ser agrupados em ações de Gestão Educacional e Desenvolvimento Técnico-Pedagógico, que se constituem nas duas grandes áreas fins da política educacional.

No âmbito da Gestão Educacional podem ser registrados os seguintes avanços:

- Universalização do acesso de crianças e adolescentes de 7 a 14 anos ao ensino fundamental (98\%);

- Promoção do acesso de $92 \%$ da população de 15 a 17 anos à escola, sendo que $27 \%$ no ensino médio no ano de 2000 ;

- Redução do índice de abandono escolar no ensino fundamental de 13,2\% em 1995 para 10,5\% em 1999;

- Implantação do maior programa de regularização do fluxo escolar de educação básica no Brasil com a metodologia do Telecurso 2000 (Projeto Tempo de Avançar) atingindo 100.604 no ensino fundamental e 39.983 no ensino médio no ano 2000;

- Expansão da Educação de Jovens e Adultos, cuja matrícula cresceu 232,69\% entre 1996 e 2000 ;

- Promoção da inclusão social de crianças com necessidades especiais, através da implantação do atendimento integrado em escolas públicas e regularização das escolas indígenas;

- Municipalização de $82,9 \%$ do ensino fundamental de $1^{\text {a }}$ a $4^{\text {a }}$ série e $53,5 \%$ de $5^{\text {a }}$ a $8^{\text {a }}$ série (ano 2001);

- Estadualização de 99\% da matrícula pública no ensino médio (2001);

- Democratização da escola pública, com a implantação dos Conselhos Escolares em todas escolas estaduais e com realização de eleição de diretores em toda a rede estadual de ensino nos anos de 1995 e 1998;

- Implantação e consolidação de três sistemas de Gestão Escolar: o Sistema Permanente de Avaliação Educacional do Ceará (SPAECE, 1992), Sistema Integrado de Gestão Educacional (SIGE, 1997) e o Sistema de Acompanhamento Pedagógico (SAP, 1996); 
- Negociação e aprovação do empréstimo de U\$ 90 milhões, específico para o setor educacional, com o Banco Mundial (Projeto de Qualificação da Educação Básica - PQEB);

- Descentralização da gestão, planejamento e acompanhamento educacional com a criação dos 21 Centros Regionais de Desenvolvimento da Educação;

- Escolarização da merenda em toda a rede estadual.

- Desenvolvimento de parcerias, como a que foi estabelecida com o Unicef (Censo Educacional Comunitário), com o Pacto de Cooperação (Fórum da Educação) e com o Poder Judiciário (Movimento Justiça na Educação);

- Concurso Único de Professores organizado pela SEDUC com a parceria de 153 municípios. Pela primeira vez, estado e municípios se unem a fim de fazer um concurso para professores de acordo com os mesmos critérios, com a finalidade de implantar um padrão comum na escolha e contratação de pessoal para o magistério das redes estadual e municipais.

- Participação na III e IV Bienal Internacional do Livro de Fortaleza (1998 e 2000), com aquisição de acervo para as escolas da rede estadual realizada diretamente pelo Núcleo Gestor da Escola;

$\mathrm{Na}$ área de Desenvolvimento Técnico-Pedagógico destacam-se:

- Implantação dos Ciclos de Formação que em 2000 foi universalizada na rede estadual e conta com o acompanhamento realizado pelo Centro Regional de Desenvolvimento da Educação e pelo Sistema de Acompanhamento Pedagógico para dar suporte aos professores do ensino fundamental, buscando a melhoria da qualidade na educação no estado do Ceará, de forma a repercutir no índice de rendimento dos alunos.

- Promoção do programa público de formação inicial docente em serviço MAGISTER CEARÁ e PROFORMAÇÃO - para a rede pública estadual e municipal, com a participação das quatro universidades públicas;

- Redução do número de professores não habilitados que passou de 21,9\% em 1995 para 15,0\% em 2000.

- Operacionalização do Projeto ESCOLA VIVA, um dos projetos de educação de maior ação interinstitucional, com envolvimento dos setores da educação, ação social, saúde, cultura e ciência e tecnologia, transformando a escola no pólo de uma comunidade de aprendizagem;

- Promoção do protagonismo juvenil através do Festival de Talentos da Escola Pública (FESTAL 2000) e da política de estímulo à organização dos grêmios estudantis;

- Promoção da educação infantil municipal, com a criação de Comissões Regionais e Municipais de Educação Infantil. 


\section{Acesso à educação básica}

Por muito tempo o acesso à escola foi privilégio de poucos. A escola pública de melhor qualidade (rara) exigia uma prova seletiva para nela ingressar ou um cartão de apresentação de alguém influente. Recursos públicos financiavam bolsas de estudo distribuídas por critérios particulares. Embora a população rural preponderasse sobre a urbana, a oferta de escola pública concentrava-se nas áreas urbanas dos pólos regionais (Fig. 1).

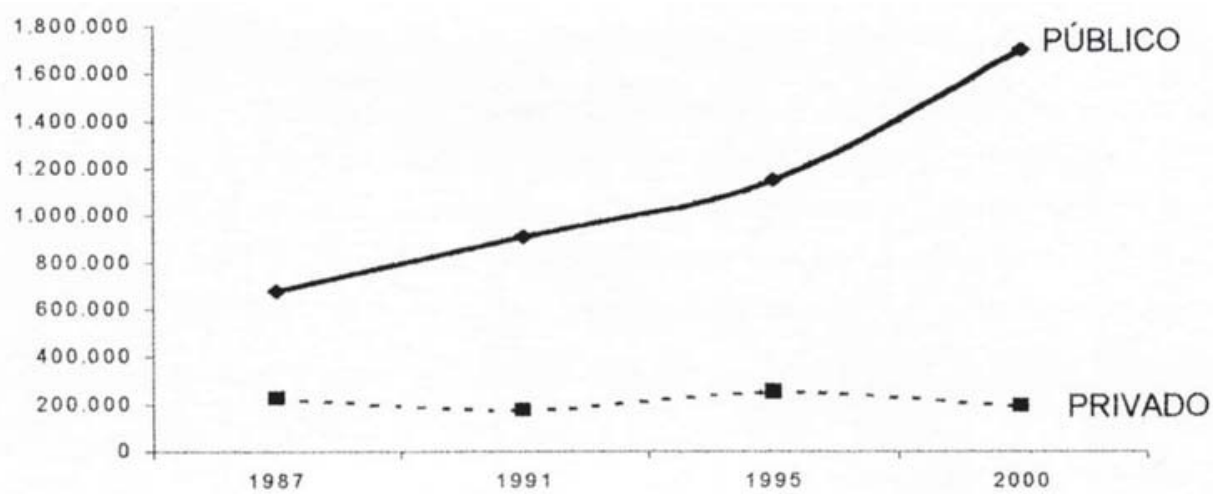

Fonte: SEDUC/CPPE/Central de Dados

Figura 1

Matrícula no Ensino Fundamental

Ceará - 1987/200

Nos últimos cinco anos, constatamos um crescimento acelerado da matrícula na rede pública, tanto do ensino fundamental quanto no médio. A rede particular registrou uma perda de matrícula na educação básica, no mesmo período. Ao estabelecer um paralelo entre o Ceará, Nordeste e Brasil, verificamos que no período compreendido entre 1995 e 2000 a matrícula do ensino fundamental no Brasil cresceu $9,3 \%$, no Nordeste $26,3 \%$ e no Ceará $35,4 \%$. No ensino médio, a matrícula brasileira, no mesmo período, cresceu $52,4 \%$, enquanto no Nordeste cresceu $68 \% \mathrm{e}$ no Ceará 99\%, incluindo-se o Tempo de Avançar - ensino médio (Fig. 2).

Atualmente, o acesso não é mais o problema fundamental, pois $98 \%$ das crianças e adolescentes de 7 a 14 anos estão matriculadas nas escolas. Mas não é apenas com as tradicionais providências relacionadas com o acesso que será resolvido o problema das crianças que continuam fora da escola. O caso é mais complexo. É de inclusão, o que implica em ações mais abrangentes de política social. Simultaneamente, são necessárias providências para garantir a permanência e o sucesso escolar, relacionados, portanto, com a qualidade. Nesse sentido, o Estado organizou e implantou o ensino em Ciclos de Formação, criou as Classes de Aceleração e vem desenvolvendo um Sistema de Acompanhamento Pedagógico envolvendo toda a rede pública de ensino. 


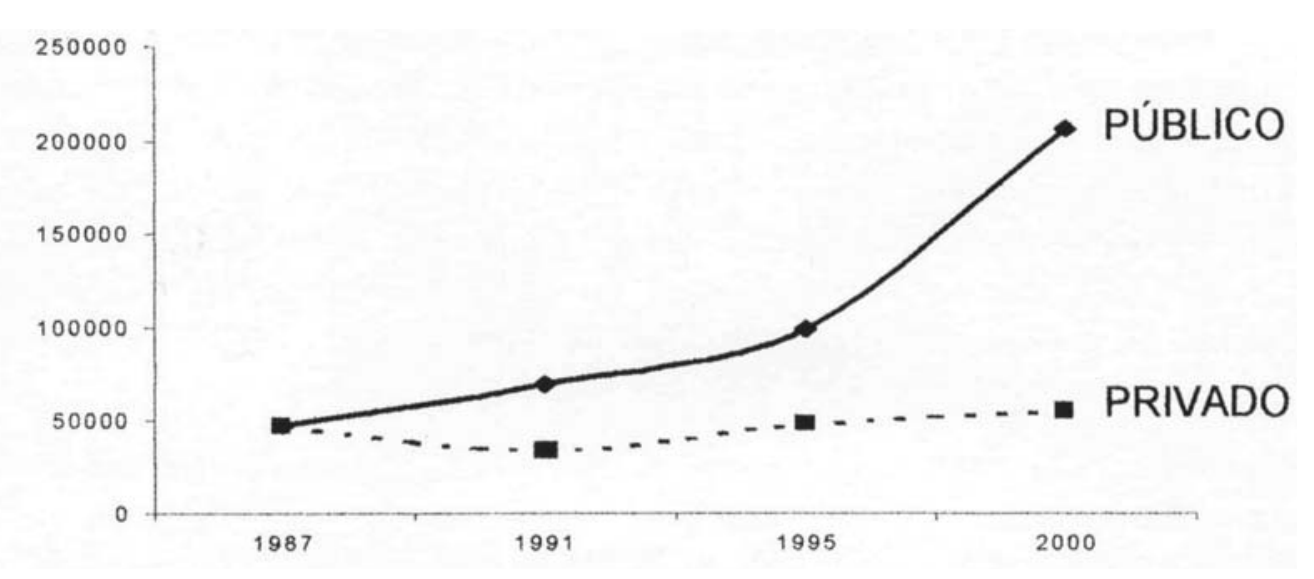

Fonte: SEDUC/CPPE/Central de Dados

Figura 2

Matrícula no Ensino Médio

Ceará - 1987/200

Visando aumentar a escolaridade e as oportunidades educacionais da população economicamente ativa na faixa etária de 15 a 39 anos, a SEDUC desenvolveu ações de alfabetização de adultos e regularização do fluxo escolar do ensino fundamental e médio, como o Programa Alfabetização Solidária.

Adotando o maior programa de regularização do fluxo escolar da educação básica no Brasil, com a metodologia do Telecurso 2000, a SEDUC implantou, no ano 2000 o projeto Tempo de Avançar, oportunizando, através de convênio com a Fundação Roberto Marinho e Editora Globo, aceleração da escolaridade de cearenses na faixa etária de 15 a 29 anos.

Ao todo foram instaladas 4.111 tele-salas em 2.893 unidades escolares, sendo atendidos 100.604 alunos de ensino fundamental e 39.983 alunos do ensino médio. Dos 184 municípios cearenses, 174 aderiram ao programa, entretanto, em todos eles existem telesalas instaladas nas escolas estaduais. O programa desenvolvido ofereceu uma iniciativa inédita de estímulo aos professores, visando a erradicação do déficit de educação básica entre jovens e adultos, com prioridade para os jovens 15 a 29 anos, sem formação no ensino fundamental. Uniram-se, num empreendimento do Instituto Multiplicar, empresas privadas, instituições governamentais e internacionais que reconhecendo e incentivando as atividades dos professores do projeto Tempo de Avançar, em parceria com o governo do estado do Ceará e a Fundação Roberto Marinho, remuneraram através de bônus em dinheiro no valor de R $\$ 20,00$ por disciplina e por aluno, o bom desempenho dos professores dos 50.000 alunos que tiveram melhor aproveitamento na conclusão do Ensino Fundamental, o que resultou no bônus médio de R \$ 2.000 por professor. 
O ano de 1998 marca a grande virada dos indicadores educacionais no estado, com a superação das metas propostas no início da década e o alcance da universalização técnica do ensino fundamental registrada pela cobertura de $98 \%$ de matrículas entre crianças e jovens de 7 a 14 anos. Contribuíram para esta superação a Lei e o processo de municipalização (1996), o pacto por Toda Criança na Escola em Fortaleza, a Matrícula Única da Rede Pública e a implantação do Fundo de Manutenção e Desenvolvimento do Ensino Fundamental e Valorização do Magistério (FUNDEF).

Entre 1987 e 1998, o crescimento da matrícula total do ensino fundamental foi de $103 \%$, havendo uma tendência de decréscimo na rede particular, registrada a partir de 1995 e a definição de responsabilidades entre as redes públicas estadual e municipal. A tendência de crescimento da rede municipal foi acelerada com a municipalização do ensino, a partir do ano de 1995, conforme pode ser observado no gráfico abaixo que revela os efeitos da política de colaboração estado e municípios.

Analisando a evolução da matrícula do ensino fundamental público no período de 1996 a 2001 observa-se (fig. 3) que houve um movimento simétrico de crescimento da matrícula municipal ( de 60,5\% em 1996 para $77,8 \%$ em 2001) e redução da matrícula estadual (de 39,5 \% em 1996 para 22,2\% em 2001).

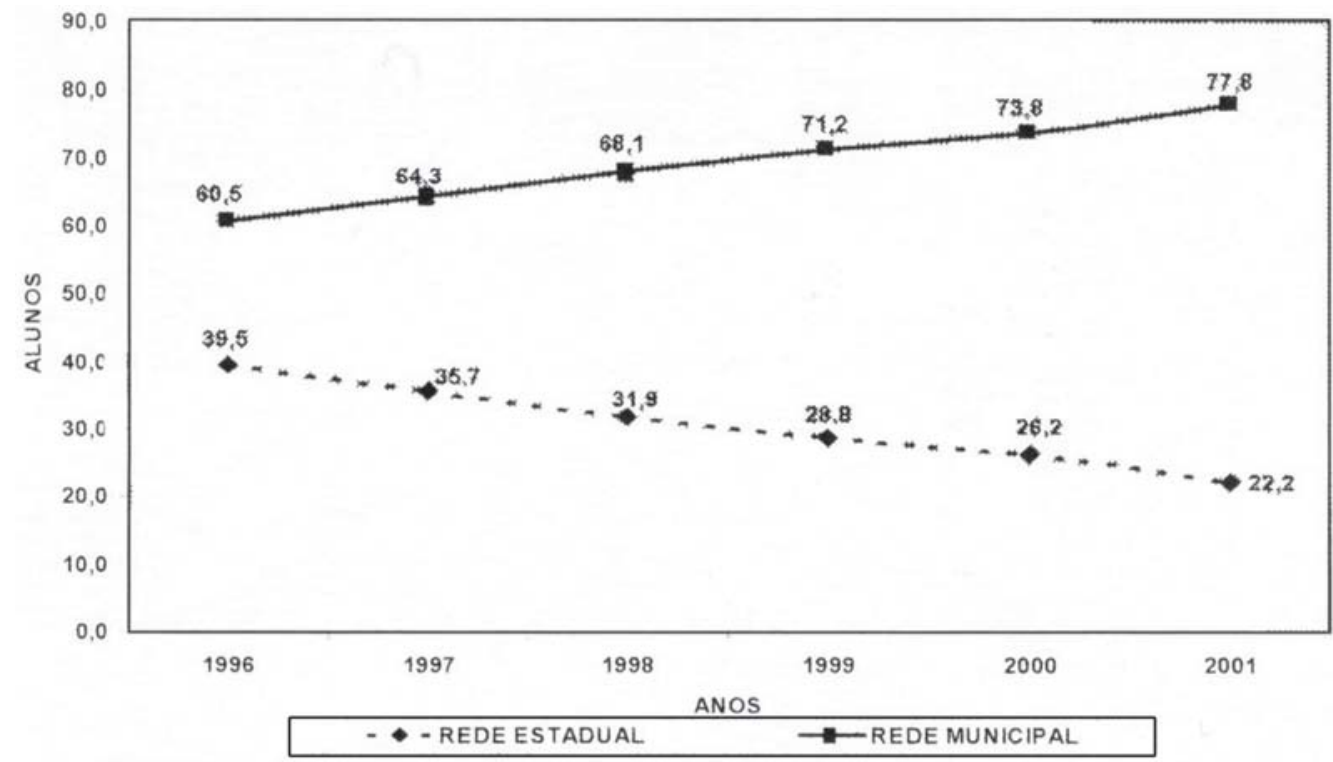

Fonte: SEDUC/CPPE/Central de Dados

Figura 3

Matrícula no Ensino Fundamental

Estado/Município

Ceará - 1996/200 
Na figura 4, o movimento inverso pode ser percebido em relação à matrícula inicial de ensino médio no mesmo período. A universalização do ensino fundamental e a definição de seu financiamento por meio do FUNDEF tem gerado um impacto sobre a educação infantil e o ensino médio. Na educação infantil, algumas alternativas estão sendo ultimadas, como a antecipação do acesso ao ensino fundamental aos seis anos de idade, a implantação dos Ciclos de Formação, implantação das classes de aceleração e a disseminação de informações e mobilização pela expansão do atendimento, como tem feito a comissão interinstitucional de educação infantil.

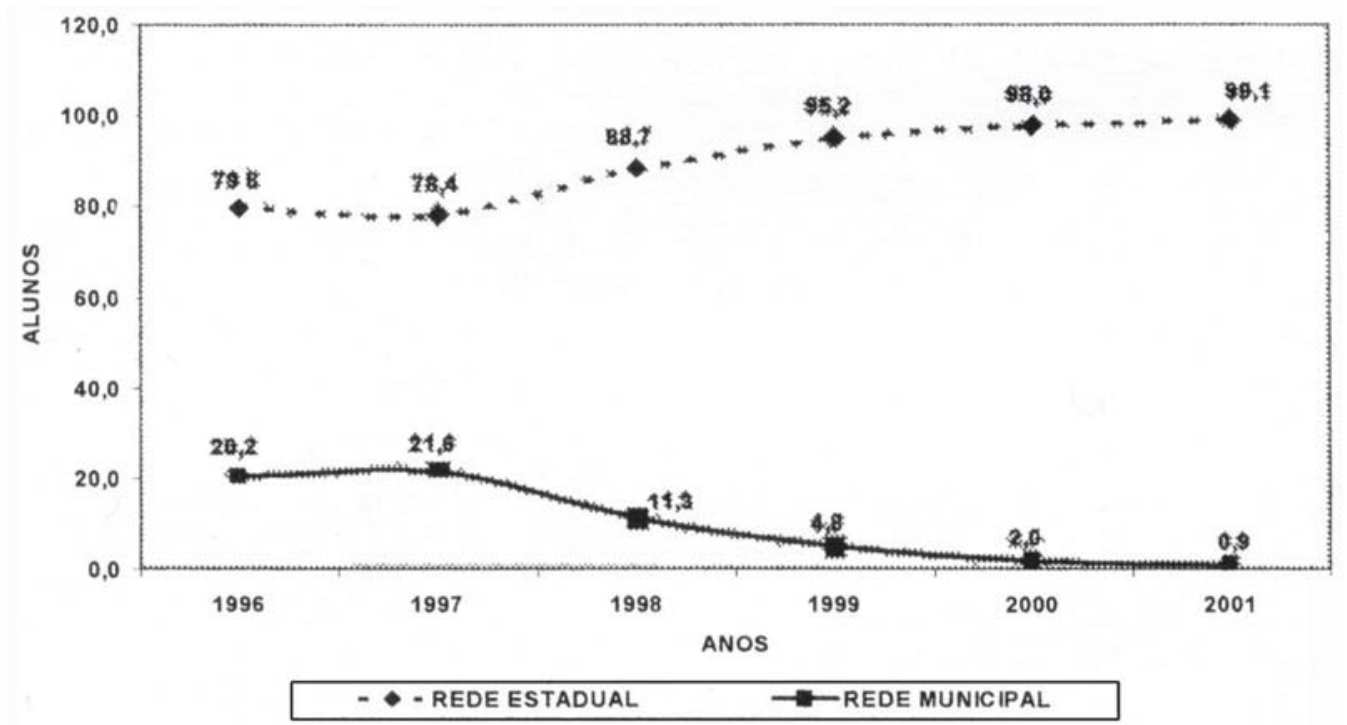

Fonte: SEDUC/CPPE/Central de Dados

Figura 4

Matrícula no Ensino Médio

Estado/Município

Ceará - 1996/200

A cobertura de $98 \%$ da população de 7 a 14 anos no ensino fundamental revela um novo desafio para a educação cearense: a inclusão social. Grande parte dos $2 \%$ de jovens e crianças fora da escola são constituídas por crianças, jovens e adultos com necessidades especiais de aprendizagem, comunidades indígenas e habitantes das periferias urbanas da capital e do interior do estado.

\section{Melhoria do desempenho dos alunos}

A melhoria da qualidade do sistema escolar implica em esforços múltiplos, no sentido da ampliação das oportunidades de acesso ao ensino fundamental, em particular para aqueles que passaram pela escola, momentaneamente, e a ela não retornaram; pelo cumprimento dos princípios de eqüidade na distribuição de 
recursos; e, na garantia dos padrões básicos de funcionamento das escolas, entendidos como aqueles que envolvem desde as instalações escolares àqueles que compreendem questões curriculares, materiais de ensino-aprendizagem e aprimoramento dos recursos humanos. A melhoria da qualidade na educação, portanto, deverá ter como pressuposto básico, a garantia de um ambiente social, escolar e familiar propício ao sucesso e permanência do aluno na escola.

Tendo como base os dados que configuram a situação educacional cearense, esta pode ser descrita, através de três curvas populacionais referenciadas ao ano de 1998, as quais descrevem: 1 a população de 7 a 17 anos; 2 o comportamento da matrícula por idade e 3 a matrícula por série, como pode ser observado na figura 5, para o ano de 1998, e na figura 6, para o ano de 2001.

A comparação entre as três curvas evidencia a elevação da matrícula no Ensino Fundamental, em que se verifica o alcance da meta técnica de universalização desse ensino em 98\% no Estado; entretanto, existe um agravamento nas taxas de distorção entre a idade e a série cursada pelo aluno, caracterizando o fenômeno distorção idade-série, atingindo uma média global de 43\%. Observa-se, ainda, a deficiência na oferta do Ensino Médio.

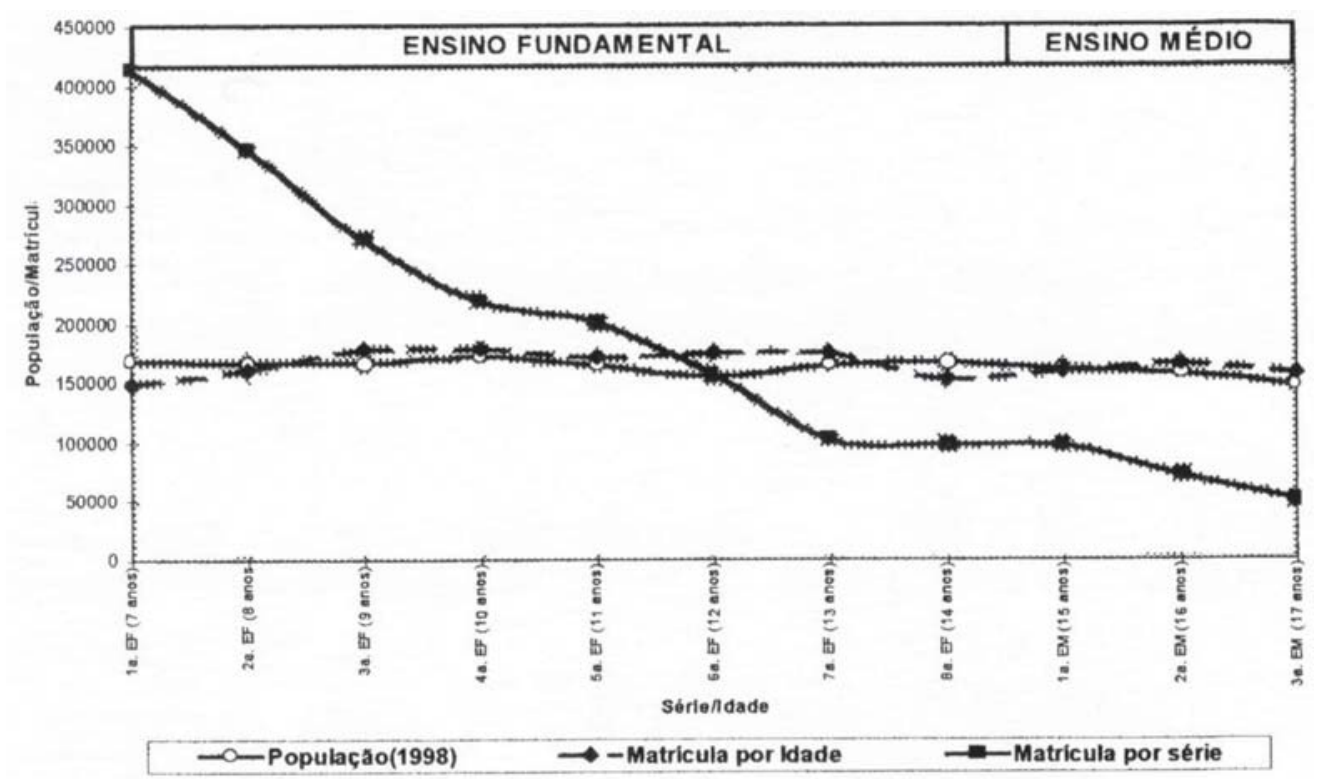

Fonte: SEDUC/CPPE/Central de Dados

Figura 5

População e matrícula inicial do Ensino Fundamental e Médio por série e idade

Ceará (1998) 


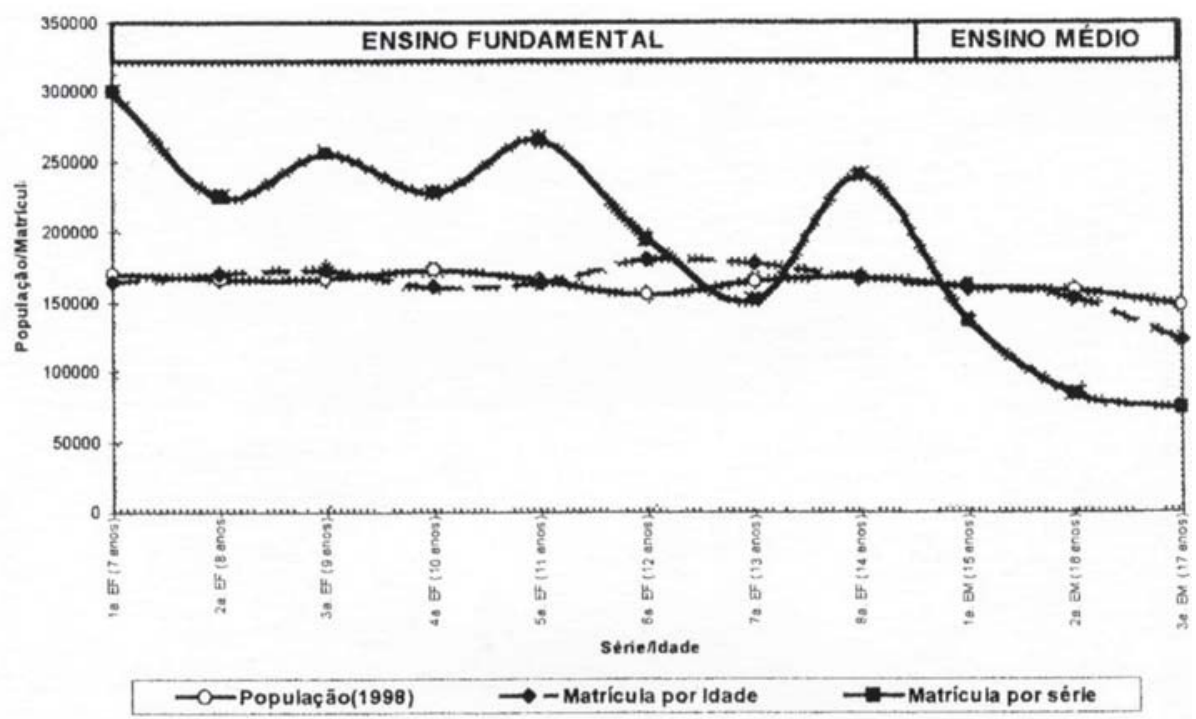

Fonte: SEDUC/CPPE/Central de Dados

Figura 6

População e matrícula inicial do Ensino Fundamental e Médio

por série e idade

Ceará (2001)

Partindo-se do princípio de que a aproximação das três curvas representaria, em termos ideais, a situação desejável, desenham-se, para o estado, múltiplos desafios que exigem mobilização de vontades e intensificação de políticas que já vêm sendo implementadas com sucesso que se traduzem na ampliação do número das classes de aceleração e dos ciclos de aprendizagem, no fortalecimento do regime de colaboração entre estado e municípios e estes entre si, na criação de ambientes autônomos de aprendizagem, no fortalecimento dos mecanismos de avaliação e acompanhamento, na antecipação do acesso de crianças de seis anos ao ensino fundamental, e ainda, no desenvolvimento de ações voltadas para a capacitação da população cearense.

As medidas tomadas entre 1998 e 2001 permitiram uma significativa mudança do fluxo escolar, como pode ser verificado na figura 7 , que compara a mudança do perfil de matrícula, por série, no ensino fundamental e médio entre 1998 e 2001.

A compreensão que se tem hoje de como se desenvolve a aprendizagem e a conseqüente e necessária mudança da prática pedagógica na sala de aula, tem constituído a referência de toda a ação curricular em desenvolvimento. E nesse aspecto, a escola está cada vez mais VIVA, valendo destacar 51 escolas de Fortaleza e 110 no interior do estado onde a música, as artes plásticas, a dança, o teatro e a informática educativa compartilham o dia-a-dia de alunos e professores, 
tornando criativo e interessante o ato de aprender e de ensinar. Aqui, merecem destaque os grupos de corais, de dança, as orquestras infanto-juvenis e o teatro voltado para a produção textual e encenação das peças produzidas pelos próprios alunos com a ajuda do professor, as quais enfocam temas da realidade social da comunidade escolar.

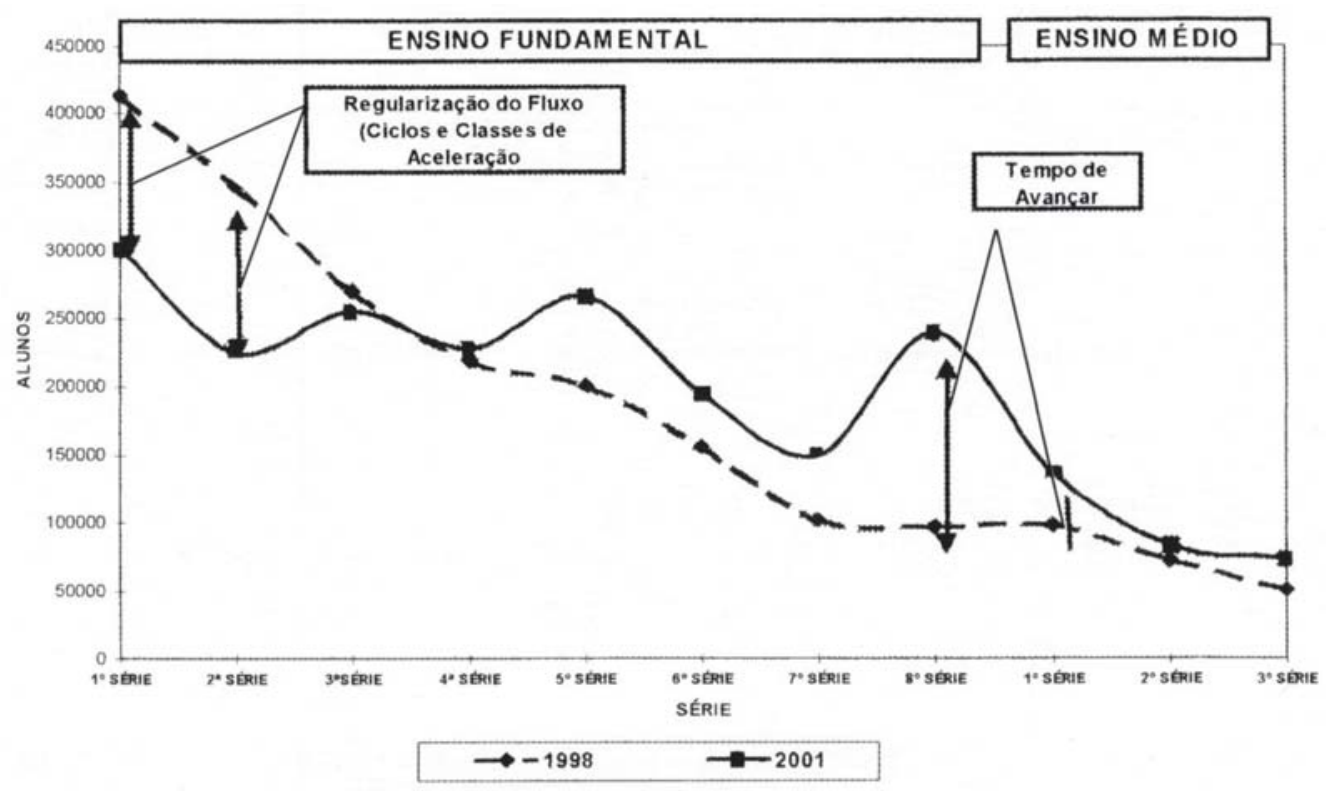

Fonte: SEDUC/CPPE/Central de Dados

Figura 7

Matrícula inicial do Ensino Fundamental e Médio por série

Ceará (1998 e 2001)

Essa concepção de aprender e ensinar implicou na execução de um amplo programa de formação continuada e em serviço dos que fazem a escola, em especial dos professores. Este programa, por sua vez, exigiu uma ação permanente de acompanhamento, criando-se o SAP (Sistema de Acompanhamento Pedagógico), em meados de 1996.

O SAP é um conjunto de atividades para detectar, ao longo do trabalho educativo e de modo permanente, os pontos fortes, passíveis de incentivo e aperfeiçoamento, bem como os pontos frágeis das ações educacionais, não atingidos pelas estratégias de melhoria da qualidade do ensino, corrigindo-os a tempo, evitando a progressão do erro, revendo, aperfeiçoando as demais ações e adequando-as ao sucesso do processo de aprendizagem do aluno. Tem duas vertentes básicas: a gestão e o ensino. 


\section{Permanência e Sucesso}

As mudanças curriculares e o sistema de acompanhamento pedagógico começam a surtir efeito. Os três principais indicadores de movimento escolar apresentaram uma substancial melhora no Ceará no período 1995-1999. A taxa de aprovação do ensino fundamental cresceu de 70,80\% (1995) para 81,53\% (1999); a taxa de abandono está em ritmo de decréscimo, tendo caído de 13,20\% (1995) para 10,52\% (1999); a taxa de reprovação caiu à metade no período, tendo passado de 16,00\% (1995) para 7,96\% (1999).

Estes números indicam que devem ser concentrados esforços no sentido de manter as crianças e jovens na escola, o que significa estimular políticas de permanência e combate ao trabalho infanto-juvenil, uma das principais causas de abandono escolar, sobretudo entre os homens.

Os indicadores de aprovação, reprovação e abandono no ensino médio seguem a mesma tendência do ensino fundamental, sendo mais grave o abandono que, apesar de ter caído de 19,10\% (1995) para 13,45\% (1999), mantêm-se em uma preocupante faixa de insucesso dos alunos e ineficiência da escola em garantir sua permanência.

\section{Gestão democrática}

O modelo de gestão preconizado no plano de governo busca viabilizar a realização das atividades de cada Pasta, com mais eficiência e agilidade, influenciando sobretudo no resultado das ações.

Essa concepção aponta para a descentralização, a redução dos níveis hierárquicos, a participação da sociedade civil nas ações do governo, a socialização das decisões e a divisão de responsabilidades.

Neste contexto, a proposta de gestão colegiada da Secretaria de Educação Básica do Ceará focaliza a escola como ponto de partida adotando mecanismos como a eleição direta para diretores de escolas, a criação do Fundo de Apoio ao Desenvolvimento da Escola (FADE), o projeto Escola Viva, a criação dos Conselhos Escolares, a Escolarização da Merenda e mais recentemente a definição do Plano de Desenvolvimento da Escola (PDE).

Reconhecer a escola como ponto de partida implica em garantir medidas à sua autonomia administrativa, pedagógica e financeira, sustentada pelo tripé: Projeto Pedagógico, Plano de Desenvolvimento da Escola e Regimento Escolar (código de ética).

O primeiro passo dado para a implementação desta política foram as eleições diretas para diretores escolares em 1995, que inauguraram na educação a forma democrática de escolha de gerentes públicos. 


\section{Eleição de divetores}

Com base no princípio, só se educa para democracia, educando-se pela democracia, aconteceu em 1995 a primeira eleição direta para diretores, assegurando a participação da comunidade na gestão escolar. Em 1998, o processo foi consolidado com um novo pleito.

Inicialmente, os candidatos foram submetidos a uma seleção de competência técnica, primeira etapa da escolha de diretor junto às escolas públicas estaduais, constituída de uma avaliação escrita e exame de títulos. Esta primeira etapa credenciou os aprovados a participarem do Núcleo Gestor da escola como diretor, coordenador pedagógico, administrativo-financeiro ou articulador comunitário, e secretário escolar.

Na segunda etapa, participaram das eleições, por meio do voto direto, pais, professores, servidores e alunos que se credenciaram na unidade de ensino junto à Comissão Escolar (composta por integrantes do Conselho Escolar). Esta é uma etapa de avaliação da empatia e liderança do candidato. Após eleito, o diretor escolheu entre os coordenadores aprovados na etapa anterior sua equipe. É necessário ressaltar que a experiência de eleger, diretamente, seus gestores escolares demonstra a importância da comunidade participar, continuamente, das atividades realizadas na escola, desde as pedagógicas às administrativas-financeiras, acompanhando o Plano de Desenvolvimento da Escola.

\section{Conselho Escolar}

A gestão escolar, assumida de forma democrática, tem o gerenciamento pedagógico e administrativo-financeiro feito com a participação efetiva e organizada de todos os segmentos da comunidade escolar. Essa participação democrática foi garantida pelo estado do Ceará através da implantação de Conselhos Escolares em todas as suas unidades de ensino.

O Conselho Escolar é o órgão colegiado constituído por pais, alunos, professores, funcionários, direção e representantes da sociedade civil organizada, escolhidos para representar a comunidade escolar. Em 1998, o Conselho Escolar desempenhou um papel fundamental durante a eleição dos diretores, mobilizando alunos, pais, professores e funcionários, coordenando o processo de discussão entre os candidatos e a comunidade escolar em torno do PDE, organizando todo o trabalho de votação, enfim, promovendo uma prática educativa democrática em busca de uma melhoria na qualidade e desempenho da escola.

\section{Valorização do magistério}

A política de educação básica do estado do Ceará, nos últimos cinco anos, vem dando ênfase a duas premissas relacionadas com o magistério: valorização e 
profissionalização. Na valorização do magistério, o Governo do estado vem promovendo uma série de ações: concurso público para funções efetivas em parceria com 153 municípios e seleção pública para cargos de confiança, além de também estar facilitando o acesso a bens culturais, como o programa Um Professor, Um Computador, beneficiando diretamente todos os professores de ciências e os diretores eleitos.

Ainda na valorização do magistério, o governo do estado, em 1995, através da lei 12.426 , de $1^{\circ} / 3 / 95$, autorizou um aumento escalonado, juntamente com a definição de um intervalo de $5 \%$ entre cada referência, com o propósito de recuperar a hierarquia salarial, estimulando a qualificação. Como resultado imediato houve um aumento médio de $52,5 \%$ dos níveis 1 a 30 do magistério. O menor aumento nas faixas iniciais, que representavam apenas $10 \%$ do conjunto de docentes, foi de 27\%. Em 1996 foi concedido novo aumento, de 19\%, exclusivamente para os professores da educação básica. Já em 1998 houve uma complementação de $4,75 \%$. Com os $6 \%$ a mais que vigoraram a partir de junho de 2000 , a categoria acumula um total que varia entre $67,8 \%$ e $104,8 \%$ a partir de 1995 .

É oportuno lembrar que, em 1995, apenas 7\% dos professores do estado tinham curso de pós-graduação, ampliando-se para 32\% atualmente, o que significa que esses professores tiveram sua remuneração aumentada em $35 \%$ decorrente de ascensão funcional, além dos reajustes salariais. O mesmo fato ocorreu com os professores que possuíam licenciatura curta. Representavam 16\% do total, em 1995, e atualmente são apenas 4\%. Ao freqüentarem curso superior, plenificando a licenciatura, tiveram um aumento na remuneração que variou de $5 \%$ a $35 \%$.

O MAGISTER está habilitando 4.202 professores da escola pública cearense, sendo 1.935 da rede estadual e 2.267 das redes municipais. Voltado para os profissionais que já detêm o nível médio (magistério ou outra formação), este programa prevê a oferta de três tipos de licenciaturas: a) Linguagens e Códigos; b) Ciências Naturais e Matemática e c) Ciências Humanas, a fim de habilitar professores para atuarem nas séries finais do ensino fundamental e do ensino médio. $\mathrm{O}$ profissional passa por uma formação em uma das áreas e aprofunda o conhecimento em uma ou duas disciplinas afins.

Ao final do curso, os professores da rede estadual passarão dos níveis iniciais em que se encontram $\left(1^{\circ}\right.$ a $\left.5^{\circ}\right)$, com formação pedagógica de nível médio para o nível 13, com formação do magistério em nível superior.

Essa mudança de nível assegura um aumento mínimo de 35\% na remuneração de cada professor. É importante destacar, também, que ao final do curso a rede estadual terá mais de $95 \%$ do seu corpo docente com nível superior, três anos antes do prazo dado pela LDB. 


\section{Desafios}

Apesar dos avanços e perspectivas abertas por tal política educacional e mesmo pelo incipiente desenvolvimento econômico, permanece o histórico desafio cearense da promoção da inclusão e da eqüidade social. Alcançados alguns êxitos, permanecem ainda alguns antigos desafios que se revestem de uma nova abordagem destes temas, em outras bases de coesão social.

No setor educacional esses temas são caracterizados pela baixa qualidade educacional, caracterizado, fundamentalmente, por um baixo acesso às oportunidades educacionais de qualidade, que promovam uma mudança significativa e permitam a inserção econômica de 60 \% da população que vive abaixo da linha de pobreza. Nesse sentido, a política educacional é apenas um dos muitos elementos da ampla reforma social que ainda está por ser construída no Ceará.

Em 2001 a política educacional cearense entra em uma nova fase, tendo como ponto de partida a escola, o seu projeto pedagógico e o seu plano de desenvolvimento institucional. A proposta é baseada, novamente, em uma ampla mobilização da sociedade para a discussão da escola que se tem e a da escola que se quer. Este movimento social em torno da educação veio a se chamar Escola do Novo Milênio, numa evidente alusão às mudanças educacionais pretendidas para o início do novo século. Este movimento procura gerar consensos dentro de um modelo de planejamento participativo gerado desde a escola, como unidade básica de planejamento, até o governo do estado, passando pelas comunidades e municípios.

A focalização na escola, anunciada com a mobilização iniciada em 1995, toma agora contornos mais visíveis, com a abertura da escola ao planejamento pela comunidade dentro do processo Escola do Novo Milênio. É presumível que essa abertura permitirá que a comunidade perceba que há muito o que fazer para promover uma mudança qualitativa nas escolas públicas cearenses.

Os pais serão recebidos por professores que estão passando por um processo de formação docente que busca universalizar a graduação em nível superior entre os professores públicos. Tal graduação, negociada com as universidades públicas do estado, permitirá que os professores tenham ganhos salariais médios de $35 \%$ ao fim do curso. As ementas desta formação prevêem uma adequação aos novos parâmetros curriculares nacionais. Apesar disso, os pais provavelmente encontrarão profissionais insatisfeitos com suas carreiras e com suas condições de trabalho.

Aqui parece estar o ponto central, talvez o ponto de inflexão e mutação da política educacional cearense - a promoção da qualidade a partir da sala de aula e liderada pelos atores que permanecem na escola - os professores. Como no palco, a consolidação da reforma educacional cearense, obrigatoriamente, deve ter 
pelo menos três focos: alunos, professores e comunidade, abrigados pelo espaço físico da escola.

Esta focalização deverá traduzir-se em políticas como: a) acordo setorial em torno da garantia das condições mínimas de educabilidade dos alunos, algo que foge à função social da escola; b) formação, profissionalização e protagonismo docente para o desenvolvimento de processos de aprendizagem em um ambiente de freqüentes mudanças científicas, tecnológicas e sociais; c) capacitação ampla da população em temas de participação e educação familiar; d) flexibilização e diversificação da oferta de serviços educacionais, sobretudo para jovens e adultos; e) promoção da inclusão e equidade de acesso à educação de qualidade, sobretudo nas áreas rurais remanescentes e áreas periféricas das maiores cidades e f) estender o conceito de universalização à educação infantil e ao ensino médio.

Esta segunda geração de reformas educacionais exigirá a articulação de três conceitos básicos de gestão educacional cearense: autonomia escolar, descentralização e avaliação.

Estes conceitos articulam-se a partir da autonomia escolar. Há que se promover os padrões básicos de funcionamento das escolas em toda a rede pública para que se possa estabelecer uma sólida política de avaliação educacional, que por sua vez deve estar, necessariamente, construída por um moderno sistema de acompanhamento pedagógico, mais ágil e focalizado nas demandas escolares e não apenas na manutenção de políticas curriculares.

Neste sentido, há que se aumentar os esforços de construção de um regime de colaboração entre Estado e Municípios, no setor educacional, que além de consolidar o processo de descentralização, permita a definição de um sentido de atuação, a partir da fundação de um pacto que garanta o desenvolvimento de políticas convergentes em torno de uma escola pública, democrática, de qualidade e sustentável.

\section{Conclusões}

A segunda geração de reformas educacionais cearenses encontrará atores mais exigentes e informados. Do outro lado da mesa de negociações, provavelmente um estado mais pobre, ocupando-se dos pobres cearenses, que tendem a crescer, já que o Ceará não tem governabilidade sobre o cenário econômico nacional. Poderá ocorrer o grande paradoxo de uma política exitosa ser inviabilizada em sua continuidade em função da concorrência com outras áreas, talvez até menos eficientes, mas de um apelo social maior, como a de geração de emprego e renda, saúde e segurança pública.

O sistema educacional cearense deverá mostrar os resultados desta política em um prazo menor do que o que seria aceitável em condições econômicas mais 
favoráveis. A sua sustentabilidade depende do seu sucesso e capacidade de adaptação às mudanças científicas, econômicas e sociais. O bom uso dos recursos financeiros a serem aportados pelo empréstimo em fase de negociação com o Banco Mundial é a chave de um cofre que dá acesso a outros cofres.

Ademais, o conceito de sustentabilidade não se traduz apenas em recursos financeiros, senão também em sustentabilidade social. Como a proposta educacional cearense está baseada na mobilização social e no regime de colaboração, é imprescindível a contabilização do sucesso para que se mantenha o nível de coesão conseguido e que se possa ampliar, agregando aqueles atores que não foram suficientemente envolvidos na primeira fase de reformas. Especial atenção deve ser dada, então, aos professores, agentes, definitivamente, indissociáveis da consolidação das reformas.

Antenor Naspolini é secretário da Educação Básica do estado do Ceará. 